\title{
FEATURE
}

\section{The role of turmeric (curcumin) in gingival health}

This article is adapted from a poster dental therapy student Magdalena Mackay created, based on a literature review she conducted in the third year of her degree at the University of the Highlands and Islands in Inverness.

\section{What is gingivitis?}

- Gingivitis is a reversible inflammatory condition initiated by a composition of a biofilm and microbial community known as dental plaque

- Dental plaque is tolerant to environmental stress, host defences and antimicrobial agents. $^{1}$

How do we treat it?

- The most effective method of removing supra-gingival dental plaque is by mechanical plaque removal with the use of a toothbrush, interdental aids or professional oral prophylaxis

- Anti-plaque mouthwashes such as chlorhexidine are supported as temporary measures for acute conditions. ${ }^{2}$

\section{Introduction}

- Turmeric is commonly used as a culinary additive

- Turmeric is also used in medicine, as an antiseptic, anti-inflammatory, antioxidant and for wound healing ${ }^{3}$

- Over recent years, the interest in curcumin research has increased and shown that curcumin exhibits anti-inflammatory activity by suppressing the pro-

inflammatory transcription. ${ }^{4}$

Why does this interest us?

- There may be clinical benefits to be gained from the critical analysis of the emerging research in natural medicine

- Dental care professionals (DCPs) should be able to treat patients more holistically by respecting their views on pharmaceuticals

- The General Dental Council (GDC) advocates to treat patients as individuals.

\section{Aim}

- To summarise and evaluate the evidence on the efficiency of curcumin when compared to chlorhexidine for the management of plaque-induced gingivitis.

\section{Method}

- PubMed, Web of Science and Knowledge Network were utilised as primary literature search tools
- Boolean search method was utilised with the following search terms: turmeric $O R$ curcumin OR curcuma AND chlorhexidine AND gingivitis AND dental plaque.

\section{Results}

- The reviewed studies demonstrated that curcumin and chlorhexidine had similar efficacy for decreasing plaque and gingival indices

- Curcumin and chlorhexidine have comparable anti-plaque and antiinflammatory properties in gingivitis

- Fewer side effects were noted for curcumin when compared to chlorhexidine.

'You must treat patients as individuals. You should take their specific communication needs and preferences into account where possible and respect any cultural values and differences. ${ }^{5}$

\section{References}

1. Eaton K, Ower P. Practical periodontics. Edinburgh: Elsevier, 2015.

2. Scottish Dental Clinical Effectiveness 
Programme. Prevention and treatment of periodontal diseases in primary care. June 2014. Available at: http://www.sdcep. org.uk/wp-content/uploads/2015/01/ SDCEP+Periodontal+Disease+Full+ Guidance.pdf (accessed 14 September 2020).

3. Aggarwal B, Sundaram C, Malani N, Ichikawa H. Curcumin: The Indian Solid Gold. In: The molecular targets and therapeutic uses of curcumin in health and disease. New York: Springer, 2007. Available at: https://link.springer.com/ chapter/10.1007/978-0-387-46401-5_1 (accessed September 2021).

4. Gupta S, Patchva S, Koh W, Aggarwal B. Discovery of curcumin, a component of the golden spice, and its miraculous biological activities. Clin Exp Pharmacol Physiol 2012; 39: 283-299.

5. General Dental Council. Standards for the dental team. 2013. Available at: https://standards.gdc-uk.org/Assets/pdf/ Standards\%20for\%20the\%20Dental\%20 Team.pdf (accessed 14 September 2020).

\section{Useful resources}

1. Anitha V, Rajesh P, Shanmugam M, Meena Priya B, Prabhu S, Shivakumar V. Comparative evaluation of natural curcumin and synthetic chlorhexidine in the management of chronic periodontitis as a local drug delivery: a clinical and microbiological study. Indian J Dent Res 2015; 26: 53-56.

2. Anusha D, Chaly P E, Mohammed J, Nijesh J, Shivashankar K, Shyam S. Efficacy of a mouthwash containing essential oils and curcumin as an adjunct to nonsurgical periodontal therapy among rheumatoid arthritis patients with chronic periodontitis: a randomized controlled trial. Indian J Dent Res 2019; 30: 506-511.

3. Arunachalam L, Sudhakar U, Vasanth J, Khumukchum S, Selvam V. Comparison of anti-plaque and anti-gingivitis effect of curcumin and chlorhexidine mouth rinse in the treatment of gingivitis: A clinical and biochemical study. J Indian Soc Periodontol 2017; 21: 478-483.

4. Chatterjee A, Debnath K, Rao N. A comparative evaluation of the efficacy of curcumin and chlorhexidine mouthrinses on clinical inflammatory parameters of gingivitis: A double-blinded randomized controlled clinical study. J Indian Soc Periodontol 2017; 21: 132-137.

5. Collins W, Walsh T, Figures K. A handbook for dental hygienists. 4th edition. Edinburgh: Wright, 1999.

6. Critical Appraisal Skills Programme. CASP
Checklist. Available at: https://casp-uk. net/casp-tools-checklists/ (accessed 2 November 2020).

7. Dahiya P, Kamal R, Gupta R, Bhardwaj R, Chaudhary K, Kaur S. Reactive oxygen species in periodontitis. J Indian Soc Periodontol 2013; 2013; 17: 411-416.

8. Farjana H N, Chandrasekaran S C, Gita B. Effect of oral curcuma gel in gingivitis management - a pilot study. J Clin Diagn Res 2014; doi: 10.7860/ JCDR/2014/8784.5235.

9. Garg R. Methodology for research I. Indian J Anaesth 2016; 60: 640-645.

10. Greenhalgh T. How to read a paper. The basics of evidence-based medicine. 5th edition. London: Wiley Blackwell, 2014.

11. Greene P R, Jackson M. The periodontium, tooth deposits and periodontal disease. In Ireland R (ed). Clinical textbook of dental hygiene and therapy. pp 99-130. Oxford: Blackwell Munksgaard, 2006.
17. Muglikar S, Patil K C, Shivswami S, Hegde R. Efficacy of curcumin in the treatment of chronic gingivitis: a pilot study. Oral Health Prev Dent 2013; 11: 81-86.

18. Puig Silla M, Montiel Company J M, Almerich Silla J M. Use of chlorhexidine varnishes in preventing and treating periodontal disease. A review of the literature. Med Oral Patol Oral Cir Bucal 2008; 13: E257-260.

19. Pulikkotil S, Nath S. Effects of curcumin on crevicular levels of IL- $1 \beta$ and CCL28 in experimental gingivitis. Aust Dent J 2015; 60: 317-327.

20.Santi S S, Casarin M, Grellmann A P, Chambrone L, Zanatta F B. Effect of herbal mouthrinses on dental plaque formation and gingival inflammation: A systematic review. Oral Dis 2019; 27: 127-141.

21. Scottish Dental Clinical Effectiveness Programme. Management of Acute Dental Problems During COVID-19 Pandemic.

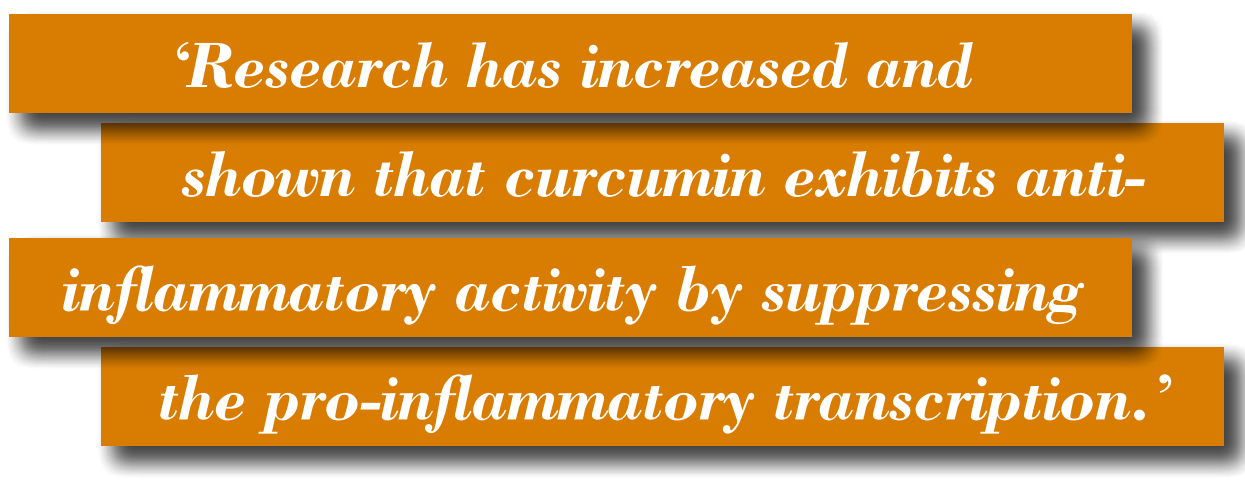

12. James $\mathrm{P}$, Worthington $\mathrm{H}$, Parnell $\mathrm{C}$ et al. Chlorhexidine mouthrinse as an adjunctive treatment for gingival health. Cochrane Database Syst Rev 2017; 3: CD008676.

13. Kandwal A, Mamgain R K, Mamgain P. Comparative evaluation of turmeric gel with $2 \%$ chlorhexidine gluconate gel for treatment of plaque induced gingivitis: A randomized controlled clinical trial. Ayu 2015; 36: 145-150.

14.Löe H, Silness J. Periodontal disease in pregnancy. I. Prevalence and severity. Acta Odontol Scand 1963; 21: 533-551.

15. Mali A, Behal R, Gilda S. Comparative evaluation of $0.1 \%$ turmeric mouthwash with $0.2 \%$ chlorhexidine gluconate in prevention of plaque and gingivitis: $\mathrm{A}$ clinical and microbiological study. J Indian Soc Periodontol 2012; 16: 386-391.

16. Mhaskar R, Emmanuel P, Mishra S, Patel S, Naik E, Kumar, A. Critical appraisal skills are essential to informed decision-making. Indian J Sex Transm Dis AIDS 2009; 30: 112-119.
2020. Available at: https://www.sdcep.org. uk/wp-content/uploads/2020/03/SDCEPMADP-COVID-19-guide-300320.pdf (accessed 2 December 2020).

22. Singh V, Pathak A K, Pal M, Sareen S, Goel K. Comparative evaluation of topical application of turmeric gel and $0.2 \%$ chlorhexidine gluconate gel in prevention of gingivitis. Natl J Maxillofac Surg 2015; 6: $67-71$.

23. Turesky S, Gilmore N D, Glickman I. Reduced plaque formation by the chloromethyl analogue of victamine C. J Periodontol 1970; 41: 41-43.

24. Waghmare P F, Chaudhari A U, Karhadkar V M, Jamkhande A S. Comparative evaluation of turmeric and chlorhexidine gluconate mouthwash in prevention of plaque formation and gingivitis: a clinical and microbiological study. J Contemp Dent Pract 2011; 12: 221-224.

https://doi.org/10.1038/s41407-021-0708-7 